Original Research

\title{
The Perception of Indonesian Nursing Students on the Learning Environment in Clinical Practice
}

\author{
Pepin Nahariani ${ }^{1}$, Fahruddin Kurdi ${ }^{2}$ and Ratna Puji Priyanti ${ }^{2}$ \\ ${ }_{1}^{1}$ Department of Fundamental Nursing and Nursing Management, STIKES Pemkab Jombang, East Java, \\ Indonesia \\ ${ }^{2}$ Department of Medical-Surgical and Emergency Nursing, STIKES Pemkab Jombang, East Java, Indonesia
}

\begin{abstract}
Introduction: The clinical practice environment students have multiple roles as learners and service providers. At this time students are faced with a fluctuating, complex environment and far from the predictions and controls of academic teachers. The aim of this study was to evaluate nursing student satisfaction and perception of the learning environment in clinical practice.
\end{abstract}

Methods: This study used correlational analytic survey methods with cross-sectional approach. A total of 164 nursing student were selected using a convenience sampling. The data were collected in three schools of nursing in East Java. Data were obtained using the Bahasa version of the Clinical Learning Environment, Supervisions and Nurse Teacher (CLES+T). The instrument showed good validity and reliability. The data were analyzed using descriptive analytic, Spearman rho correlation and logistic regression.

Results: Respondents were 164 students, clinical learning practice is mainly determined by the role of nurse teacher $(M=3.82 ; S D=0.496)$. Student satisfaction obtained at $56.7 \%$. There was a significant relationship between clinical practice learning and student satisfaction with $p$-value 0.000 . The highest correlation value is the role of lecturer nurse ( $\mathrm{r}=0.544$ ), with value $\mathrm{R}^{2}=0.377$, the coefficient of $\beta$ adjusted highest to 2.075 .

Conclusion: According to student perceptions, the content of supervisory relations, the pedagogy atmosphere in the ward/room and the role of the nurse lecturer contributed greatly to creating a conducive clinical learning environment.

\section{ARTICLE HISTORY}

Received: September 19, 2018

Accepted: March 11, 2019

\section{KEYWORDS}

clinical learning environment; nursing education; nursing students

\section{CONTACT}

Pepin Nahariani

\section{$\bowtie \quad$ ns.ratnapuji@gmail.com}

$\doteq$ Department of Fundamental Nursing and Nursing Management, STIKES Pemkab Jombang, East Java, Indonesia

Cite this as: Nahariani, P., Kurdi., F., Priyanti, R. P. (2018). The Perception of Indonesian Nursing Students on the Learning Environment in Clinical Practice. Jurnal Ners, 13(2), 233-237. doi:http://dx.doi.org/10.20473/in.v13i2.9770

\section{INTRODUCTION}

Clinical learning practice for nursing students is an important part of the learning process because of the gap between theory and practice (Myrick \& Yonge, 2005). Clinical teaching practice encourages students to prepare themselves in applying the theories gained during academic education into the clinical practice environment (Allan, Smith, \& O'Driscoll, 2011). During the student clinic learning to be very vulnerable (Chan, 2001), nursing students were asked to apply theories directly to the patient as well as about the assessment of nursing staff regarding the actions taken (Chan, 2003). While in the clinical practice environment students have multiple roles as learners and service providers (Hoffman \& Donaldson, 2004). At this time students are faced in a fluctuating, complex environment and far from the predictions and controls of academic teachers. While in the clinical practice environment nursing student's has a close bond with the real work environment, in which nursing students' has multiple roles as learners 
and service providers (Allan et al., 2011; Chan, 2003; Ip \& Chan, 2005; Papp, Markkanen, \& von Bonsdorff, 2003).

Therefore, the nursing student faced conflict in clinical learning, besides the role conflict students are also faced with the fear of hurting patients and making mistakes (Chan, So, \& Fong, 2009; Elliott, 2002; Moscaritolo, 2009). Students feel that their limited knowledge and other anxieties will impact the mistakes they make in clinical learning on career paths when they graduate (Elliott, 2002). All forms of conflict and challenges faced by students in clinical practice, of course, can not be separated from the guidance of academic lecturers. The role of nursing lecturers in clinical teaching practice is important. A nursing lecturer is someone who knows the nursing dedication, custody of clinical placement, as well as student skills and expertise (Papp et al., 2003). However, the characteristics of the nurse lecturers that want perfection from student performance lead to another source of anxiety for students (Saarikoski, Warne, Kaila, \& Leino-Kilpi, 2009).

Thus, based on the perception of nursing students, the conducive clinical practice learning environment is highly conquered (Antohe, Riklikiene, Tichelaar, \& Saarikoski, 2016). The environment in which the atmosphere supports students to learn recognizes wrongdoing, provides full moral support, as part of the learning process (Warne et al., 2010). So they can build their full capacity during the learning process. For that, an evaluation of the clinical practice learning environment is needed. An assessment of the clinical practice learning environment of nursing student perceptions, and satisfaction of clinical practice learning as one of the strategies to create an effective and conducive learning environment. However, there is lack information about nursing student perceptions and satisfaction of clinical learning environment in Indonesia. The aim of this study was to evaluate the nursing student satisfaction and perception of the learning environment in clinical practice and hospital-based supervision.

\section{MATERIALS AND METHODS}

This study used correlational analytic survey method with a cross-sectional approached. The study population is the nursing student school of nursing in Indonesia. The population was nursing students in three schools of nursing in East Java Province, Indonesia, as many as 214 people. A total of 180 respondents was selected by a convenience sampling technique. Convenience sampling is a type of nonprobability sampling where members of the target population that meet certain practical criteria, such as easy accessibility, geographical proximity, availability at a given time, or the willingness to participate in the study (Etikan, Musa, \& Alkassim, 2016).

The clinical learning environment, supervision and nurse teacher variable was assessed by Clinical
Learning Environment Scale + Nurse Teacher (CLES+T) based on the fundamental theory of clinical learning (Saarikoski, Isoaho, Warne, \& Leino-Kilpi, 2008). The instrument consists of 34 statements divided into five sub-dimensions, namely the atmosphere of learning strategy (pedagogy) in ward (9 statements), supervision relationship (8 statements), headroom or ward managers (4 statements), and the role of lecturer nurse (9 statements). Also, one sub-dimension was about student satisfaction in clinical practice. The nursing student assessment used ordinal scale: very dissatisfied, dissatisfied, neutral, satisfied and very satisfied. Reliability for this instrument has been reported using Cronbach's alpha with values ranging from 0.96 (height) to 0.77 (marginal) (Saarikoski, 2002).

The English version of the CLES+T had been translated into backward-forward Indonesian by using international guides (Epstein, Santo, \& Guilemin, 2015). The result of Content Validity Indexfor Scale (S-CVI) obtained 0.9405, while the validity test using Principal Component Analysis (PCA) test with $\mathrm{N}=46$, obtained eigenvalue and explanation percentage of $67 \%$, and Cronbach alpha of 0.786 (Priyanti \& Nahariani, 2016). These results were similar to the results of validity and reliability in the development of English version of the instrument, PCA 67\% and Cronbach alpha of 0.90 (Saarikoski, 2002).

\section{Data Collection}

The data were collected from students practicing clinical learning from three schools of nursing in East Java. All of those students were in the fifth year or doing professional nursing stage in hospital. They were offered to participate in this study by giving an explanation of research subject sheet. This explanation contained the research title and objectives, the name of principal investigator, and the address of the principal investigator. Students filling out the inform consent were considered willing to participate in this study. In addition, prospective respondents would also get a procedure to answer the questionnaire. All data were analyzed using SPSS version 17 for Windows and p values of less than 0.05 would be considered statistically significant. The data were analyzed using Spearman rho correlation for bivariate analysis and logistic regression for multivariate analysis.

\section{Ethical Considerations}

The ethical clearance had been obtained from the Faculty of Nursing Universitas Airlangga's Health Research Ethics Committee number 228-KEPK dated August 12 th, 2016. An anonymity, and coding systems are used in the analysis of research data to respect the rights and privacy of respondents. During the study, respondents were not forced to undergo research and did not have any impact on the respondents. 
Table 1 Characteristics of the Respondents $(\mathrm{N}=164)$

\begin{tabular}{|c|c|c|}
\hline Variables & $\mathbf{n}$ & $\%$ \\
\hline \multicolumn{3}{|l|}{ Age } \\
\hline 20-22 years & 89 & 54.3 \\
\hline 23-35 years & 70 & 42.7 \\
\hline $26-28$ years & 5 & 3.0 \\
\hline \multicolumn{3}{|l|}{ Gender } \\
\hline Male & 49 & 29.9 \\
\hline Female & 115 & 70.1 \\
\hline \multicolumn{3}{|l|}{ Practice Stage } \\
\hline Mental Health Nursing & 13 & 7.9 \\
\hline Community Nursing & 33 & 20.1 \\
\hline Medical-Surgical Nursing & 62 & 37.8 \\
\hline Pediatric Nursing & 26 & 15.9 \\
\hline Maternity Nursing & 15 & 9.1 \\
\hline Gerontological Nursing & 14 & 8.5 \\
\hline Emergency Nursing & 1 & 0.6 \\
\hline
\end{tabular}

Table 2 Clinical Learning Environment, Supervision and Nurse Teacher CLES+T (N=164)

\begin{tabular}{lccc}
\hline Sub Dimension & M & SD & SE \\
\hline Pedagogical Atmosphere in The Ward & 3.64 & 0.461 & 0.036 \\
Leadership Style of The Ward manager & 3.76 & 0.539 & 0.042 \\
Premises of Nursing on The Ward & 3.65 & 0.476 & 0.037 \\
Supervisory Relationship & 3.83 & 0.426 & 0.033 \\
Role of Nurse Teacher & 3.82 & 0.496 & 0.039
\end{tabular}

Table 3 Supervisory Relationship ( $\mathrm{N}=164)$

\begin{tabular}{|c|c|c|}
\hline Variables & n & $\%$ \\
\hline \multicolumn{3}{|l|}{ Title of supervisor } \\
\hline Nurse & 33 & 20.1 \\
\hline Nurse Specialist & 5 & 3.0 \\
\hline Assistant ward manager & 34 & 20.7 \\
\hline Ward manager & 92 & 56.1 \\
\hline \multicolumn{3}{|l|}{ Supervisory Status } \\
\hline I did not have a supervisor at all & 7 & 4.3 \\
\hline A personal supervisor was named, but the relationship with this person did not work during the placement & 18 & 11.0 \\
\hline The named supervisor changed during the placement, even though no change had been planned & 15 & 9.1 \\
\hline The supervisor varied according to shift or place of work & 43 & 26.2 \\
\hline The same supervisor had several students and was a group supervisor rather than an individual supervisor & 61 & 37.2 \\
\hline A personal supervisor was named and our relationship worked during this placement & 20 & 12.2 \\
\hline \multicolumn{3}{|l|}{ Supervision Frequency } \\
\hline Not at all & 39 & 23.8 \\
\hline Once or twice during the course & 39 & 23.8 \\
\hline Less than once a week & 20 & 12.2 \\
\hline About once a week & 56 & 34.1 \\
\hline More often & 10 & 6.1 \\
\hline
\end{tabular}

\section{RESULTS}

The total of respondents collected from three schools of nursing was 180 out of 214 nursing students. In the tabulation and coding stage, 16 respondents were deleted due to missing data. Thus, the total number of respondents without missing data that were analyzed by statistics was 164 respondents. Respondents' age ranged from 20 to 28 years, with more than half were 20-22 year-olds (89; 54.3\%). In regards to the gender, the most of respondents were female $(115 ; 70.1 \%)$. In addition, the most of respondents $(62 ; 37.8 \%)$ practiced at medical- surgical nursing stage which had the largest participants (Table 1).
The CLES+T scale had mean values of each subdimension ranged from 3.64 to 3.83 . The value of the content of the supervisory relationship is given the highest score with $\mathrm{M}=3.83$; $\mathrm{SD}=0.426$ (Table 2). More than half of students were supervised by ward managers $(92 ; 56.1 \%)$, and as many as 61 respondents (37.2\%) obtained one supervisor same for one group. As many as 56 respondents (34.1\%) stated that the supervision frequency was once in a week (Table 3).

Student's satisfaction with the clinical learning environment was also evaluated. More than half of the students said they were satisfied and very satisfied with the clinical learning process by 120 respondents (73.2\%) (Table 4). Based on the result of bivariate 
Table 4 Students Satisfaction in Clinical Practice $(\mathrm{N}=164)$

\begin{tabular}{lcc}
\hline Category & $\mathbf{n}$ & \% \\
\hline Very Dissatisfied & 1 & 0.6 \\
Not Satisfied & 2 & 1.2 \\
Neutral & 41 & 25 \\
Satisfied & 56.7 \\
Very Satisfied & 93 \\
Total & 27 & 16.5 \\
\hline
\end{tabular}

Table 5. Student's Satisfaction with five Sub-Dimension of the CLES+T Scale

\begin{tabular}{lrr}
\hline Sub-Dimension & r & p \\
\hline Pedagogical Atmosphere in The Ward & 0.425 & 0.000 \\
Leadership Style of The Ward manager & 0.355 & 0.000 \\
Premises of Nursing on The Ward & 0.357 & 0.000 \\
Supervisory Relationship & 0.410 & 0.000 \\
Role of Nurse Teacher & 0.544 & 0.000 \\
Total & 0.497 & $<0.0001$ \\
\hline
\end{tabular}

Table 6. Regression Analysis of Student's Satisfaction with CLES+T

\begin{tabular}{|c|c|c|c|c|c|}
\hline \multirow{2}{*}{ Model } & \multicolumn{2}{|c|}{ Unstandardized Coefficients } & \multirow{2}{*}{$\begin{array}{c}\begin{array}{c}\text { Standardized } \\
\text { Coefficients }\end{array} \\
\text { Beta } \\
\end{array}$} & \multirow[t]{2}{*}{$\mathbf{t}$} & \multirow{2}{*}{ Sig. } \\
\hline & B & Std. Error & & & \\
\hline (Constant) & 0.227 & 0.456 & & 0.498 & 0.619 \\
\hline Pedagogical Atmosphere in The Ward & -0.696 & 0.218 & -0.451 & -3.191 & 0.002 \\
\hline $\begin{array}{l}\text { Leadership Style of The Ward } \\
\text { manager }\end{array}$ & -0.660 & 0.171 & -0.500 & -3.863 & 0.000 \\
\hline Premises of Nursing on The Ward & -0.875 & 0.213 & -0.586 & -4.103 & 0.000 \\
\hline Supervisory Relationship & -0.705 & 0.222 & -0.423 & -3.183 & 0.002 \\
\hline Role of Nurse Teacher & 3.892 & 0.663 & 2.075 & 5.872 & 0.000 \\
\hline
\end{tabular}

statistic analysis, there was a significant correlation between student satisfaction with the five subdimensions CLES+T scales. The value ranges from 0.355-0.544. This coefficient correlation can be interpreted as low to moderate correlation (Sugiyono, 2008). The role of the nurse teacher obtained the biggest value $=0.544$ (Table 5).

The result of regression analysis as a whole between the five sub-dimensions of CLES+T scale obtained significant value with value $p$-value 0.000 lower than $\alpha$-value equal to 0.05 , and value of $F$ equal to 19.122 , with value $\mathrm{R}^{2}=0.377$. Among the five subdimensions of CLES+T, the role of nurse teacher, get the positive result of $\beta$-adjusted coefficient of 2.075 , with a significant value $\mathrm{p}$-value 0.000 lower than $\alpha$ value of 0.05 . Based on these results, it can be interpreted that for every 1-unit increase in nurse teacher sub-dimension, the nursing students' satisfaction will increase by the beta coefficient value (Table 6).

\section{DISCUSSION}

Nursing student perception of their clinical learning environment was described in five sub dimensions of the CLES+T. The supervisory relationship has the highest average among others. Most of the nursing student had describe that the supervisor as one supervisor for several students and the supervision meeting was once a week. In addition, most of nursing students were satisfied of the clinical learning environment. Which, the nurse teacher role has the highest impact of nursing student's satisfaction.
In this study, students consider the role of the nurse teacher is very important for students in the achievement of the clinical learning process (Kurdi, Nahariani, \& Priyanti, 2018; Saarikoski et al., 2009). This is not in accordance with previous research, it was mentioned that the connection of supervision, culture, organizational structure, and room atmosphere could affect the clinical learning environment (Flott \& Linden, 2016; Mikkonen, Elo, Kuivila, Tuomikoski, \& Kääriäinen, 2016; Saarikoski, 2002). Service quality provides a great role in student clinical learning environments (Dimitriadou, Papastavrou, Efstathiou, \& Theodorou, 2015; Papastavrou, Lambrinou, Tsangari, Saarikoski, \& Leino-Kilpi, 2010; Warne et al., 2010), and nursing staff as role models in providing professional services to patients (Papp et al., 2003).

The learning of nursing clinics, influenced by the atmosphere of the ward/room, organizational structure and supervision (Saarikoski et al., 2008). The ward atmosphere is said to play an important role in the success of clinical learning (Saarikoski et al., 2008; Warne et al., 2010). The role of lecturers has little to do with clinical learning practices (Papp et al., 2003).

Based on the results of the study, in Indonesia, the role of nursing lecturers becomes very important for students in creating an effective clinical learning environment. Students become satisfied with the learning process if nurse lecturers are actively involved in clinical practice learning. Next is the atmosphere of learning in the room. The atmosphere 
is not a conducive atmosphere, resulting in the students get their own pressure in doing clinical teaching practice. Although it is mentioned that the preceptorship model according to previous researchers is considered to be most appropriate in clinical teaching practice (Clayton, Broome, \& Ellis, 1989; Happell, 2009; Myrick \& Yonge, 2005; Udlis, 2008). The limited number of clinical preceptors, resulting in the supervisors who are assigned to the clinical practice learning is only one person for one group. Moreover, the high workload of nurses, most nurses who served as supervisors are ward or head managers.

The study has conducted as the basic information of student perception and satisfaction of clinical earning environment. This basic information can be used to evaluate the clinical learning environment. The result can be used to determine the conducive learning environment, and the suitable methods of clinical environment. The further study needs to determine the effectiveness of each methods of supervision and supervisor.

Nursing education curriculum in Indonesia in addition to academic education, clinical learning is needed to improve the competence of graduates. Clinical learning aims to equip students with a clinical competency, with a direct approach to patients to improve professional competence (Allan et al., 2011; Chan, 2003; Elisabeth, Christine, \& Ewa, 2009). In complex and unpredictable clinical learning, students become susceptible to stress and affecting the learning process (Chan et al., 2009; Elliott, 2002; Ip \& Chan, 2005; Moscaritolo, 2009; Papp et al., 2003). Therefore, creating conducive learning environment for nursing student is necessary. The selection of supervisors, type of supervision, room atmosphere and pedagogical atmosphere in clinical learning is an important consideration in planning clinical learning for nursing students.

\section{Limitations}

This study has many limitations, one of which is the convenience sampling method and only three schools of nursing in one province. A small number of samples may also affect the results of the study.

\section{CONCLUSION}

Overall, according to student perceptions, the content of supervisory relations, the pedagogy atmosphere in the ward or room and the role of the nurse teacher dominantly contributed in creating a conducive clinical learning environment. So that the results of research can be used as information about the role of teachers in creating a conducive clinical practice environment for students.

Further research is suggested to use a larger sample size and can represent the clinical learning environment in Indonesia as a whole. And using educational institutions with preceptorship learning model as a comparison with the method of learning one supervisor for one group.

\section{Acknowledgment}

We thank to STIKES Pemkab Jombang who has funded this research with the Institutional Research Grant, Dr. Mikko Saarikoski who has given permission in the use of instruments.

\section{REFERENCES}

Allan, H. T., Smith, P., \& O'Driscoll, M. (2011). Experiences of supernumerary status and the hidden curriculum in nursing: a new twist in the theory-practice gap? Journal of Clinical Nursing, 20(5-6), 847-855.

Antohe, I., Riklikiene, O., Tichelaar, E., \& Saarikoski, M. (2016). Clinical education and training of student nurses in four moderately new European Union countries: Assessment of students' satisfaction with the learning environment. Nurse Education in Practice, 17, 139-144.

Chan, C. K. L., So, W. K. W., \& Fong, D. Y. T. (2009). Hong Kong baccalaureate nursing students' stress and their coping strategies in clinical practice. Journal of Professional Nursing, 25(5), 307-313.

Chan, D. (2001). Development of an innovative tool to assess hospital learning environments. Nurse Education Today, 21(8), 624-631.

Chan, D. S. K. (2003). Validation of the clinical learning environment inventory. Western Journal of Nursing Research, 25(5), 519-532.

Clayton, G. M., Broome, M. E., \& Ellis, L. A. (1989). Relationship between a preceptorship experience and role socialization of graduate nurses. Journal of Nursing Education, 28(2), 72-75.

Dimitriadou, M., Papastavrou, E., Efstathiou, G., \& Theodorou, M. (2015). Baccalaureate nursing students' perceptions of learning and supervision in the clinical environment. Nursing \& Health Sciences, 17(2), 236-242.

Elisabeth, C., Christine, W.-H., \& Ewa, P. (2009). Teaching during clinical practice: Strategies and techniques used by preceptors in nursing education. Nurse Education Today, 29(5), 522526.

Elliott, M. (2002). Clinical environment: a source of stress for undergraduate nurses. Australian Journal of Advanced Nursing, 20(1), 34-38.

Epstein, J., Santo, R. ., \& Guilemin, F. (2015). Epstein, J., Santo, R. M., \& Guillemin, F. A review of guidelines for cross-cultural adaptation of questionnaires could not bring out a consensus. Journal of Clinical Epidemiology, 68(4), 435-441.

Etikan, I., Musa, S. A., \& Alkassim, R. S. (2016). Comparison of convenience sampling and purposive sampling. American Journal of Theoretical and Applied Statistics, 5(1), 1-4.

Flott, E. A., \& Linden, L. (2016). The clinical learning environment in nursing education: a concept analysis. Journal of Advanced Nursing, 72(3), 501513.

Happell, B. (2009). A model of preceptorship in nursing: Reflecting the complex functions of the 
role. Nursing Education Perspectives, 30(6), 372376.

Hoffman, K. G., \& Donaldson, J. F. (2004). Contextual tensions of the clinical environment and their influence on teaching and learning. Medical Education, 38(4), 448-454.

Ip, W. Y., \& Chan, D. S. K. (2005). Hong Kong nursing students' perception of the clinical environment: a questionnaire survey. International Journal of Nursing Studies, 42(6), 665-672.

Kurdi, F., Nahariani, P., \& Priyanti, R. P. (2018). Komponen evaluasi lingkungan belajar klinik, supervisi dan dosen perawat. Journal of Health Sciences, 11(1).

Mikkonen, K., Elo, S., Kuivila, H.-M., Tuomikoski, A.-M., \& Kääriäinen, M. (2016). Culturally and linguistically diverse healthcare students' experiences of learning in a clinical environment: A systematic review of qualitative studies. International Journal of Nursing Studies, 54, 173187.

Moscaritolo, L. M. (2009). Interventional strategies to decrease nursing student anxiety in the clinical learning environment. Journal of Nursing Education, 48(1), 17-23.

Myrick, F., \& Yonge, O. (2005). Nursing preceptorship: Connecting practice and education. Lippincott Williams \& Wilkins.

Papastavrou, E., Lambrinou, E., Tsangari, H., Saarikoski, M., \& Leino-Kilpi, H. (2010). Student nurses experience of learning in the clinical environment. Nurse Education in Practice, 10(3), 176-182.

Papp, I., Markkanen, M., \& von Bonsdorff, M. (2003). Clinical environment as a learning environment: student nurses' perceptions concerning clinical learning experiences. Nurse Education Today, 23(4), 262-268.

Priyanti, R. P., \& Nahariani, P. (2016). Skala evaluasi lingkungan belajar klinik, supervisi dan dosen perawat (Clinical Learning Environment, Supervision and Nurse Teacher-CLES+T) versi bahasa indonesia: Validitas dan reliabilitas. Journal of Health Sciences, 9(2).

Saarikoski, M. (2002). Clinical learning environment and supervision. Development and validation of the CLES evaluation scale. University of Turku.

Saarikoski, M., Isoaho, H., Warne, T., \& Leino-Kilpi, H. (2008). The nurse teacher in clinical practice: developing the new sub-dimension to the clinical learning environment and supervision (CLES) scale. International Journal of Nursing Studies, 45(8), 1233-1237.

Saarikoski, M., Warne, T., Kaila, P., \& Leino-Kilpi, H. (2009). The role of the nurse teacher in clinical practice: an empirical study of Finnish student nurse experiences. Nurse Education Today, 29(6), 595-600.

Sugiyono. (2008). Metode penelitian pendidikan: (pendekatan kuantitatif, kualitatif dan $R \& D$ ). Alfabeta. Retrieved from https://books.google.co.id/books?id=0xmCnQAA CAAJ

Udlis, K. A. (2008). Preceptorship in undergraduate nursing education: An integrative review. Journal of Nursing Education, 47(1), 20-29.

Warne, T., Johansson, U.-B., Papastavrou, E., Tichelaar, E., Tomietto, M., Van den Bossche, K., ... Saarikoski, M. (2010). An exploration of the clinical learning experience of nursing students in nine European countries. Nurse Education Today, 30(8), 809-815. 